\title{
ASPECTOS DA POLINIZAÇÃO DE Ouratea spruceana ENGL. (OCHNACEAE) OCORRENTE NA RESERVA BIOLÓGICA DE CAMPINA - INPA
}

\author{
Angelic Katz Nara ${ }^{1}$ \\ Martinho Alves de Andrade Júnior ${ }^{2}$ \\ Pedro Ivo Soares Braga ${ }^{3}$
}

\begin{abstract}
RESUMO: O presente estudo foi realizado na Reserva Biológica de Campina (INPA), durante o período de 22 a 26 de maio de 1996.0 objetivo foi estudar os aspectos relacionados à polinização da Ouratea spruceana. A espécie apresenta flores amarelas vistosas de antese diurna, odor adocicado e anteras poricidas, atraindo principalmente abelhas Euglossa sp. Este inseto apresenta o habito de vibrar o abdomen quando pousado sobre os estames e estigma, sendo considerado o provável polinizador. Foram aplicados cinco tratamentos (xenogamia, geitonogamia, apomixia, auto polinização e auto polinização espontânea) em flores de seis indivíduos. A principal forma de reprodução de Ouratea spruceana é provavelmente por xenogamia.
\end{abstract}

Palavras-chaves: Polinização; Ouratea spruceana; xenogamia.

ABSTRACT: The present study was carried out in the Campina Biological Reserve (INPA) from may 22 to 26, 1996. The aim was to study some aspects of pollination in Ouratea spruceana. This species produces showy yellow flowers, with diurnal anthesis, a sweetish odor and stamens dehiscing by apical pores and they attract mainly bees Euglossa sp. This insect has the habit of vibrating its abdomen when it alights on the stamens and stigma and is considered to be the probable pollination agent. Five types of pollinating processes were tested for in six different individuals (xenogamy, geitonogamy, apomixy, self-pollination and spontaneous self-pollination). Xenogamy is probably the main reproduction form of Ouratea spruceana.

Key words: pollination; Ouratea spruceana; xenogamy.

1. Mestranda em Botânica/INPA - Manaus/AM

Mestrando em Botânica/INPA - Manaus/AM; Museu Integrado de Roraima/Setor de Botânica

3 Prof. Dr. do Departamento de Biologia da Universidade do Amazonas Manaus/AM

Bol. do Mus. Integrado de Roraima, Boa Vista, 4 (único):11-22, 1998 


\section{INTRODUÇÃO}

A família Ochnaceae é de distribuição pantropical, com grande concentração de gêneros e espécies na América sultropical (HEYWOOD, 1978). NEE (1995), relata que existem aproximadamente 30 gêneros e 400 espécies, com a maioria estando presente nos trópicos. MAAS \& WESTRA (1993) citam o gênero Ouratea com cerca de 120 espécie nos Neotrópicos.

Em todos os relatos referentes à família Ochnaceae, encontrados na literatura consultada, o único representante lenhoso desta família na área da Reserva de Campina do INPA é Ouratea spruceana. Segundo ANDERSON et al. (1975) esta espécie parece ter um papel decisivo no processo de transição da Campina aberta para a Campina sombreada, por ser a única espécie arbórea dominante em ambas.

Vários trabalhos foram desenvolvidos na área de Reserva de Campina do INPA (ANDERSON et al., 1975; BRAGA \& BRAGA, 1975; LISBOA, 1975; CARREIRA, 1977; LISBOA, 1976; LISBOA, 1976a; BRAGA, 1977; MACEDO, 1977; BRAGA, 1979; BRAGA, 1982; GUILLAUMET, 1987; ALENCAR, 1990), porém nenhum deles se reportou ao estudo dos aspectos relacionados à polinização de Ouratea spruceana, que constitui o objetivo deste trabalho.

\section{MATERIAL E MÉTODOS}

O presente estudo foi realizado durante o período de 22 a 26 de Maio de 1996, com visitas periódicas em junho e julho, na Reserva Biológica de Campina (INPA), situada no Km 45 da BR 174 (Manaus - Caracaraí), extremo norte de Manaus, Amazonas Brasil.

O tipo de vegetação de campina é caracterizado por apresentar solo arenoso, muitas vezes exposto, formando manchas ou ilhas no meio da floresta de terra firme. Lençol freático superficial. Vegetação aberta, com árvores de pequeno porte, arbustos e arvoretas de até 5 metros de altura, tortuosas, com cascas espessas (BRAGA, 1979).

Utilizou-se a técnica do Vermelho Neutro segundo VOGEL (1962) para verificar a existência e localização de osmóforos (células produtoras de odores); Hidróxido de Amônio segundo SCOGIN et al (1977) para identificar os locais onde ocorrem reflexão dos raios ultra-violetas; Água oxigenada (10 vol.) para verificar a receptividade do estigma (aplicada em intervalos Bol. do Mus. Int. de Roraima, Boa Vista, 4 (único):11-22, 1998 
regulares a cada 2h, durante 24h); Azul de Anilina adaptado de BROWN (1960) e DARLINGTON \& LA COUR (1965) para constatar a viabilidade dos grãos de pólen; Tetrazólio segundo LEE (1967) para detectar a atividade citoplasmática dos grãos de pólen, utilizando-se microscópio óptico de marca Kyowa/Tokyo, com aumento 10 x 40 vezes (BRAGA, 1996).

Para verificar o sistema reprodutivo da espécie foram realizados 5 tratamentos (xenogamia, geitonogamia, apomixia, auto-polinização manual e auto-polinização espontânea), em 6 indivíduos escolhidos por serem os únicos a apresentarem flores na época da realização deste estudo. Além desses, foram determinadas inflorescências controle - controle com tratamento (retirada dos estames) e controle sem tratamento (flores ao natural) - afim de complementar as observações realizadas (Tab. 1). Todos os tratamentos, com exceção dos tratamentos controle, receberam o isolamento da inflorescência com o "voile". Xenogamia: retirada dos estames e polinização artificial cruzada; Geitonogamia: retirada dos estames e polinização artificial com pólen proveniente de uma flor do mesmo indivíduo; Apomixia: retirada dos estames; Autopolinização manual: retirada dos estames e polinização artificial com pólen proveniente da mesma flor; Autopolinização espontânea: retirada de botões e isolamento das flores abertas.

Entre os dias 23 e 26 de maio, registrou-se a atividade dos visitantes de Ouratea spruceana, a fim de identificar os possíveis agentes polinizadores da espécie estudada. Os indivíduos observados foram 0 de $n^{\circ} I$ e de $n^{\circ} V I$, por apresentarem maior numero de inflorescências. As observações tiveram início às 5:00 h, estendendo-se por todo o dia até às $17: 00 \mathrm{~h}$.

No primeiro e segundo dia, apenas foram observados os visitantes e registrados os horários de visitas, afim de evitar que possíveis capturas alterassem a frequência de visitas às inflorescências. No terceiro dia, os visitantes foram capturados com auxílio de "puçás". Foram registradas as visitas, e efetuadas as coletas, daqueles insetos que apresentavam comportamento de polinizadores (pousavam nas flores e vibravam as anteras promovendo a saída de jatos de pólen). Além destes, foram ainda capturados os insetos que apresentavam comportamento de predação. Considerou-se como período de antese desde o momento da abertura da flor até sua senescência.

Bol. do Mus. Integrado de Roraima, Boa Vista, 4 (único):11-22, 1998 
Tabela 1.Distribuição dos tratamentos de acordo com o número de flores abertas por indivíduo de Ouratea spruceana.

\begin{tabular}{|c|c|c|c|c|c|c|}
\hline $\begin{array}{c}\text { INDI- } \\
\text { VÍDUOS }\end{array}$ & $\begin{array}{c}\text { INFLO- } \\
\text { RESCENNCIA }\end{array}$ & TRATAMENTOS * & $\begin{array}{c}\mathrm{N}^{\circ} \mathrm{de} \\
\text { FLORES } \\
23.05\end{array}$ & $\begin{array}{c}\mathrm{N}^{\circ} \mathrm{de} \\
\text { FLORES } \\
24.05\end{array}$ & $\begin{array}{c}\mathrm{N}^{\circ} \mathrm{de} \\
\text { FLORES } \\
25.05\end{array}$ & $\begin{array}{c}\mathrm{N}^{\circ} \mathrm{de} \\
\text { FLORES } \\
26.05\end{array}$ \\
\hline \multirow{14}{*}{ I } & 01 & Xenogamia & 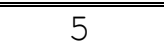 & 2 & 3 & 2 \\
\hline & 02 & Geitonogamia & 0 & 3 & 1 & 2 \\
\hline & 03 & Controle $\mathrm{S} / \mathrm{T}$ & 1 & 1 & 3 & 0 \\
\hline & 04 & Auto P/Es & 0 & 1 & 1 & 3 \\
\hline & 05 & Auto P & 0 & 0 & 2 & 0 \\
\hline & 06 & Geitonogamia & 2 & 0 & 0 & 0 \\
\hline & 07 & Auto P/Es & 1 & 0 & 0 & 9 \\
\hline & 08 & Xenogamia & 2 & 0 & 1 & 0 \\
\hline & 09 & Controle $\mathrm{C} / \mathrm{T}$ & 0 & 0 & 0 & 1 \\
\hline & 10 & Auto P/Es & 1 & 0 & 0 & 6 \\
\hline & 11 & Controle $\mathrm{S} / \mathrm{T}$ & 1 & 0 & 0 & 0 \\
\hline & 12 & Apomixia & 2 & 0 & 0 & 0 \\
\hline & 13 & Apomixia & 2 & 0 & 0 & 0 \\
\hline & 14 & Controle $\mathrm{C} / \mathrm{T}$ & 0 & 0 & 1 & 1 \\
\hline \multirow{2}{*}{ II } & 01 & Xenogamia & 1 & 1 & 1 & 5 \\
\hline & 02 & Auto P/ES & 0 & 0 & 0 & 1 \\
\hline III & 01 & Auto P/Es & 0 & 0 & 0 & 8 \\
\hline \multirow{2}{*}{ IV } & 01 & Auto P & 0 & 1 & 0 & 0 \\
\hline & 02 & Xenogamia & 1 & 0 & 2 & 2 \\
\hline \multirow{2}{*}{$\mathrm{V}$} & 01 & Controle S/T & 0 & 0 & 0 & 1 \\
\hline & 01 & Xenogamia & 1 & 0 & 2 & 0 \\
\hline \multirow{2}{*}{ VI } & 02 & Controle $\mathrm{S} / \mathrm{T}$ & 0 & 2 & 0 & 2 \\
\hline & 03 & Auto P/Es & 0 & 0 & 0 & 1 \\
\hline Total & 23 & 7 & 20 & 11 & 17 & 44 \\
\hline
\end{tabular}

*Controle $\mathrm{S} / \mathrm{T}=$ Controle sem tratamento; Controle $\mathrm{C} / \mathrm{T}=$ Controle com tratamento; Auto $\mathrm{P} / \mathrm{Es}=$ Autopolinização espontânea; Auto $\mathrm{P}=$ Autopolinização.

\section{RESULTADOS E DISCUSSÃO}

Descrição da espécie

Ouratea spruceana é uma arvoreta com até 5,0 m de altura. Inflorescência terminal, um rácemo de dicásio, ráquis ca. de $16,0 \mathrm{~cm}$ de comprimento, até 6 flores em antese, até 22 botões (Fig. 1a). Flor hermafrodita, pentâmera, simetria radial, ca. de

Bol. do Mus. Integrado de Roraima, Boa Vista, 4 (único):11-22, 1998 
2,40 - 3,15 cm de diâmetro, ca. de 1,15 - 1,40 cm de altura. Pedicelo ca. de 5,0 - 9,0 cm de comprimento. Brácteas florais 2, ovadas, côncavas, ápice agudo, dispostas bilateralmente na base do pedicelo, ca. de 0,45 - 0,55 cm de comprimento por ca. de $0,15-0,30 \mathrm{~cm}$ de largura. Cálice dialissépalo, sépalas lanceoladas, ca. de 1,10 - 1,64 cm de comprimento por ca. de 0,40 - 0,70 cm de largura, ápice agudo, cor verde na base tornado-se amarelada em direção ao ápice. Corola dialipétala, pétalas unguiculadas, ca. de 1,22 - 1,64 cm de comprimento por ca. de 0,25 - 0,26 cm de largura, ápice agudo, opostas às sépalas. Androceu dialistêmone, estames 10, sésseis, poricidas, ca. de 1,05 cm de comprimento (Fig. 1c; d) Gineceu apocárpico, estigma 1, simples, ca. de 0,95 cm de comprimento (Fig. 1e); carpelos 5, óvulo 1 por lóculo. Fruto drupáceo, constituído por 3 - 4 carpídios, sésseis sobre o receptáculo (Fig. 1b).

Características da antese

Foram estudadas um total de 92 flores distribuídas em 23 inflorescências, ao longo de 5 dias de observações. No primeiro dia, observou-se o desenvolvimento da antese e deu-se início a aplicação dos tratamentos. Estes tratamentos foram sendo aplicados ao longo do período de estudo, a medida em que as flores abriam.

A antese teve início por volta das 05:00 h, com as flores permanecendo abertas o dia inteiro. O término da antese variou de flor para flor, com flores apresentando apenas fechamento parcial das peças florais, fato este mais intensificado a partir das 17:00 h. As flores abertas em um dia não tornaram a abrir no dia seguinte.

O horário de liberação do pólen coincidiu com o início das visitas pelos supostos insetos polinizadores (por volta das $07: 00 \mathrm{~h})$. Antes disso, os insetos eram observados sobrevoando as flores, provavelmente atraídos pelo perfume, sem entretanto apresentar comportamento de polinização.

O perfume exalado pelas flores era adocicado, perceptível desde às 06:30 h, tornando-se mais intenso por volta das 09:00 h, permanecendo após o final da antese, embora menos intenso. Por volta das 20:30 h o perfume ainda era perceptível.

Bol. do Mus. Integrado de Roraima, Boa Vista, 4 (único) : 11-22 1998 

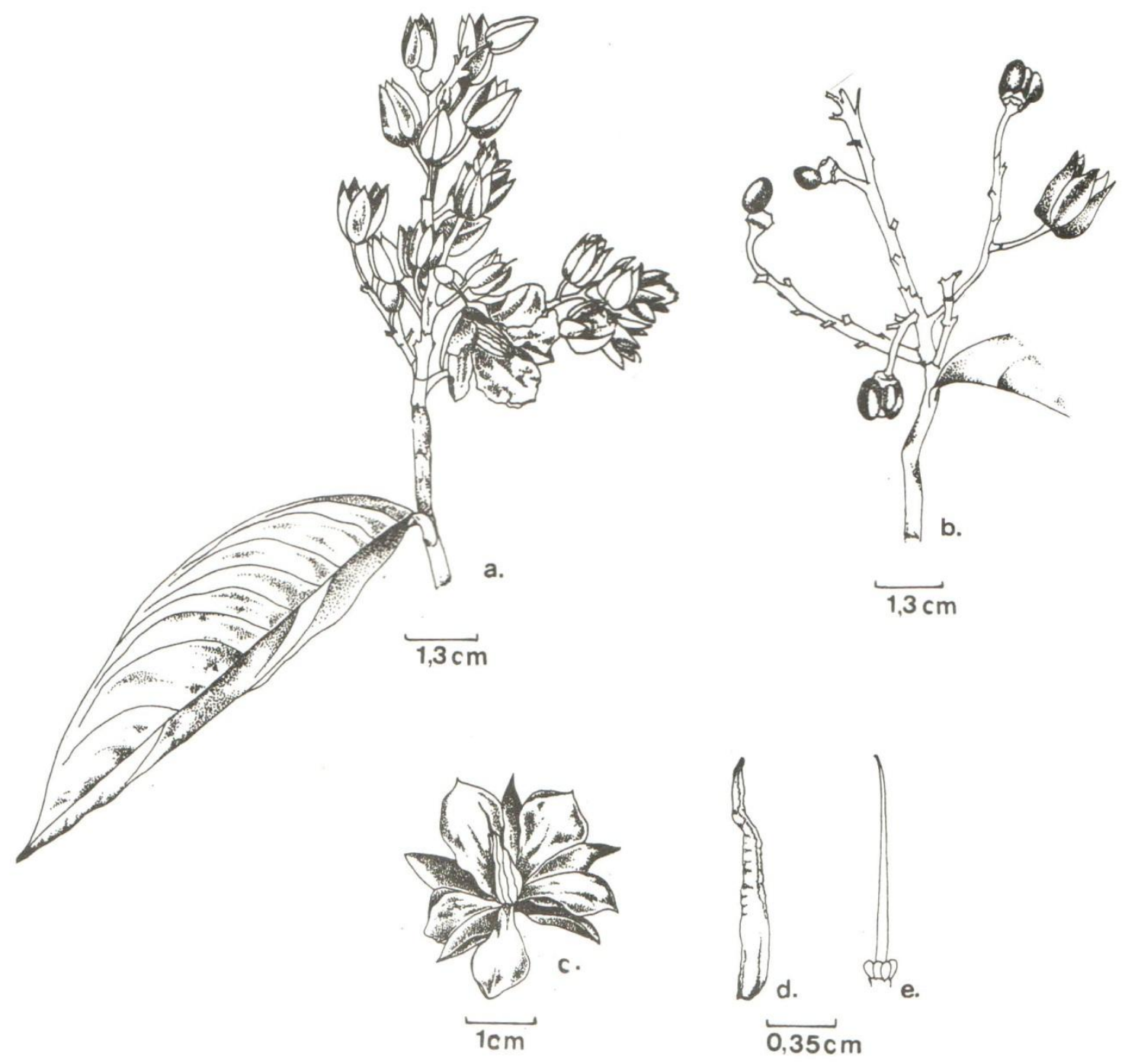

Fig. 1.Ouratea spruceana: a.inflorescência; b.infrutescência; c.aspecto gerasl da flor; d.detalhe do estame; e.detalhe do estilete e estigma.

Bol. do Mus. Int. de Roraima, Boa Vista, 4 (único): 11-22, 1998 
Não foram detectadas glândulas de néctar nas flores. Presumivelmente, a única recompensa oferecida pela planta aos agentes polinizadores é o pólen, que é liberado em quantidade, desde que ocorra o movimento de vibração das anteras.

Os resultados do teste com Hidróxido de Amônio demonstraram que praticamente toda flor reflete os raios ultravioleta, com exceção do estigma e do ápice das anteras. As pétalas coraram intensamente de alaranjado apresentando-se marrom-avermelhada na região apical. Sépalas e anteras coraram de marrom para avermelhado.

Após a utilização de Azul de Anilina e Tetrazólio observouse nas lâminas contendo pólen que mais de 80\% dos grãos de pólen apresentavam-se viáveis e com atividade citoplasmática.

Com o teste de Vermelho Neutro as pétalas coraram de vermelho nas porções medianas da base. Foram identificados osmóforos acompanhando o bordo das pétalas, desde a base até o ápice. Apenas a região do ápice das anteras e o estigma apresentaram-se intensamente corados.

Com os testes com água oxigenada verificou-se que o estigma apresentou-se receptivo durante todo o período de observação (24 h).

\section{Visitantes florais}

O horário de maior intensidade de visitas registradas foi entre $7: 00$ e 12:00 h. As abelhas do gênero Euglossa sp. apresentaram-se mais freqüentes até as 10:00 h, permanecendo cerca de 15 a 30 minutos visitando as flores de um mesmo indivíduo. Apenas uma única vez observou-se um indivíduo de mamangava (Xylocopa frontalis) visitando as flores por um período aproximado de 2 a 3 minutos.

O provável polinizador das flores de Ouratea spruceana são as abelhas Euglossa sp., que apresentam comportamento característico de vibração do abdomen quando pousadas sobre as anteras, além de terem sido as mais frequentes e apresentarem um padrão de horário de visitas. A espécie Xylocopa frontalis, apesar de realizar o comportamento de polinização, foi cogitada mais como pilhadora de pólen, uma vez que seu tamanho é muito avantajado para as flores em questão, demonstrando que as mesmas não estão adaptadas a insetos muito grandes (mamangava: cerca de $2,5 \mathrm{~cm}$ de comprimento $\times 1,0 \mathrm{~cm}$ de diâmetro).

Registrou-se um ataque de formigas do gênero Acromyrmex sp.

Bol. do Mus. Integrado. de Roraima, Boa vista, 4 (único):11-22, 1998 
na inflorescência controle do indivíduo $n^{\circ}$ IV, sendo predadas pétalas e estames. Uma espécie de gafanhoto e uma de Chrysomelidae-Galerucinae foram observados predando flores de várias inflorescências dos indivíduos $\mathrm{n}^{\circ} \mathrm{I}$ e $\mathrm{n}^{\circ} \mathrm{IV}$.

Além destes, observou-se vespas (Hymenoptera - Vespidae) que apresentaram comportamento predatório. Tais insetos perfuravam os botões florais na base do cálice, depositando ovos no interior da flor, entre os estames. Ali, observou-se o desenvolvimento da larva (através da coleta e dissecação de vários botões florais predados), que por destruir o estilete e parte das porções internas dos estames inviabiliza a fecundação.

Formação de frutos

Registrou-se a formação de frutos com 27 carpídios, 26 para - tratamento de xenogamia (indivíduos I e II) e 1 para o tratamento de autopolinização (indivíduo IV). Além destes observou-se apenas persistência de sépalas em 6 inflorescências nos indivíduos I, II e III (Tb. 2).

Tabela 2. Resultados obtidos com a aplicação dos tratamentos para caracterização do sistema de reprodução de Ouratea spruceana.

\begin{tabular}{|c|c|c|c|c|}
\hline $\begin{array}{c}\text { INDIVÍ- } \\
\text { DUOS } \\
\end{array}$ & $\begin{array}{c}\text { INFLORES- } \\
\text { CÊNCIA } \\
\end{array}$ & TRATAMENTOS & $\begin{array}{c}\mathrm{N}^{\circ} \quad \mathrm{DE} \\
\text { FLORES } \\
\end{array}$ & RESULTADOS \\
\hline \multirow{7}{*}{ I } & 01 & Xenogamia & 03 & 10 Carpídios \\
\hline & 03 & Controle $\mathrm{S} / \mathrm{T}$ & 05 & Sépala persistente \\
\hline & 04 & Auto P/Es & 04 & Sépala persistente \\
\hline & 05 & Auto $\mathrm{P}$ & 01 & Sépala persistente \\
\hline & 08 & Xenogamia & 04 & 13 Carpídios \\
\hline & 09 & Controle $\mathrm{C} / \mathrm{T}$ & 01 & Sépala persistente \\
\hline & 14 & Controle $\mathrm{C} / \mathrm{T}$ & 04 & Sépala persistente \\
\hline \multirow{2}{*}{ II } & 01 & Xenogamia & 01 & 03 Carpídios \\
\hline & 02 & Auto P/Es & 07 & Sépala persistente \\
\hline III & 01 & Auto P & 04 & Sépala persistente \\
\hline IV & 05 & Auto P & 01 & 01 Carpídio \\
\hline Total & 11 & - & 35 & 27 Carpídios \\
\hline
\end{tabular}

Bol. do Mus. Int. de Roraima, Boa Vista, 4 (único): 11-22, 1998 
Em cada flor, que apresentou formação de frutos, houve desenvolvimento de no máximo 3 carpelos (fruto composto - flor com ovário apocárpico de 5 carpelos, na base do cálice) .

O fato de não ter sido observado formação de carpídios nos testes para geitonogamia, apomixia, autopolinização manual, autopolinização espontânea e controle com tratamento, associado aos resultados obtidos com a aplicação do tratamento de xenogamia, revela uma provável condição de autoincompatibilidade dos indivíduos de Ouratea spruceana.

No caso do resultado obtido com o indivíduo IV, em que houve a formação de um carpídio para o tratamento de Autopolinização (Tb. 2), pode ter sido consequência de uma provável contaminação do material de trabalho, usado tanto para emasculação dos botões florais (tesouras, pinças), como também para a própria polinização artificial (hastes com algodão) .

Quanto a persistência de sépalas, observou-se que há correspondência com as inflorescências cujas as flores foram consideradas supostamente fecundadas no dia seguinte à sua antese, isto é, flores polinizadas, supostamente fecundadas, perdem os estames e as pétalas no dia seguinte. Quando supostamente não ocorre a fecundação, pétalas e estames murcham, permanecendo na flor. Dois meses após a aplicação dos tratamentos observou-se que algumas flores mantiveram as sépalas e apresentaram os ovários dilatados (embora enegrecidos), sem que no entanto, houvesse a formação de carpídios.

O pequeno número de carpídios produzidos pode ser consequência do período de estudo não ter abrangido a fase fenológica correspondente a máxima floração da espécie, que deve ocorrer em torno de julho (ALENCAR, 1990). Este fato justifica a existência de tão poucos indivíduos em floração, com apenas um deles apresentando-se com número razoável de inflorescências. Isto limitou a aplicação dos testes em um maior número de indivíduos e inflorescências. As visitas realizadas nos meses subsequentes confirmaram a maior abundância de flores nos indivíduos de Ouratea spruceana.

- número de carpídios formados por cada fruto, máximo de três, está de acordo com MACEDO (1977).

Bol. do Mus. Int. de Roraima, Boa vista, 4 (único): 11-22, 1998 


\section{CONCLUSÕES}

As abelhas Euglossa sp. são os prováveis insetos polinizadores de Ouratea spruceana, isto devido tanto a intensidade de visitas, quanto ao próprio comportamento de vibração do abdomen quando sobre as anteras.

O sistema de reprodução característico de Ouratea spruceana provavelmente é xenogamia.

A recompensa de alimento oferecida pelos indivíduos de ouratea spruceana é o pólen.

\section{AGRADECIMENTOS}

Agradecemos o apoio do Dr. Cláudio Ruy V. da Fonseca (Laboratório de Coleoptera - Sistemática, INPA/AM), Dra. Ana Yoshi Harada (Laboratório de Hymenoptera - Formicidae, INPA/AM), Dr. Antonio Carlos Webber (Departamento de Biologia da Universidade do Amazonas), M Sc. Francisco J. Aguillera Peralta (Biologia de Abelhas, INPA/AM), Silvio José Reis da Silva (Aluno de Mestrado em Entomologia, INPA/AM) e Sr. José Guedes (Herbario, INPA/AM) .

Ao Professor Martin Charles Nicholl pela tradução do resumo para o inglês.

\section{BIBLIOGRAFIA}

ALENCAR, J. da C. 1990. Interpretação fenológica de espécies lenhosas da campina na reserva biológica de campina do INPA ao Norte de Manaus. Acta Amazonica, 20 (único): 145-183.

ANDERSON, A. B. ; PRANCE, G. T. ; ALBUQUERQUE, B. W. P. de. 1975. Estudos sobre a vegetação das campinas amazônicas. III A vegetação lenhosa da campina da reserva biológica INPA/SUFRAMA (Manaus - Caracaraí, Km 62). Acta Amazonica, 5 (3) : 225-246.

BRAGA, M. M. N.; BRAGA, P. I. S. 1975. Estudos sobre a vegetação das campinas amazônicas. IV - Estudos ecológicos na campina da reserva biológica INPA/SUFRAMA (Manaus - Caracaraí, Km 62). Acta Amazonica, 5 (3): 211-223.

Bol. do Mus. Integrado. de Roraima, Boa Vista, 4 (único): 11-22, 1998 
BRAGA, M. M. N. 1977. Anatomia foliar de bromeliaceae da campina. Supl. Acta Amazonica, 7 (3): 74 .

BRAGA, P. I. S. 1979. Subdivisão fitogeográfica, tipos de vegetação, conservação e inventário florístico da floresta amazônica. Supl. Acta Amazonica, 9 (4): 53-80.

BRAGA, P. I. S. 1982. Aspectos biológicos das Orchidaceae de uma campina da Amazônia central. II - Fitogeografia das campinas da Amazônia brasileira. Tese de Doutoramento, Instituto Nacional de Pesquisa da Amazônia/ Fundação Universidade do Amazonas, Manaus, Amazonas, 345p.

BRAGA, P. I. S. 1996. Material Didático da Disciplina Biologia Floral. Curso de Mestrado em Botânica, PPGBTRN/INPA. (Mimeografado)

BROWN, C. A. 1960. Palynological techniques. Baton Rouge, Louisiana.

CARREIRA, L. M. M. 1977. Morfologia polínica de plantas lenhosas de campina. Acta Amazonica, 6 (3): 247-269.

DARLINGTON \& LA COUR. 1965. The handling of the Chromossomes. George Album and Univers., London.

GUILLAUMET, J. L. 1987. Some structural and floristic aspects of the forest. Experientia, 43: 241-251.

HEYWOOD, V. H. 1978. Flowering plants of world. Croom Helm, London, Sydney. $336 \mathrm{p}$.

LEE, A. E. 1967. Crescimento e desenvolvimento das plantas. Edart, São Paulo.

LISBOA, P. L. B. 1975. Estudos sobre a vegetação das campinas amazônicas. II - Observações gerais e revisão bibliográfica sobre as campinas amazônicas de areia branca. Acta Amazonica, 5 (3) : 211-223.

LISBOA, P. L. B. 1976 a. Estudos sobre a vegetação das campinas amazônicas. VI - Aspectos ecológicos de Grycoxylon inophyllum (Mart. ex Miq.) Ducke (Sapotaceae). Acta Amazonica, 6 (2): 193-211.

LISBOA, R. C. L. 1976. Estudos sobre a vegetação das campinas amazônicas. V - Brioecologia de uma campina amazônica. Acta Amazonica, 6 (2): 171-191.

MAAS, P. M.; WESTRA, L. Y. Th. 1993. Neotropical Plant Families. Koeltz Scientific Books. Germany/USA. 290 p. 
MACEDO, M. 1977. Dispersão de plantas lenhosas de uma campina amazônica. Supl. Acta Amazonica, 7 (1): 69p.

NEE, M. 1995. Flora preliminar do Projeto Dinâmica Biológica de Fragmentos Florestais (PDBFF). New York Botanical Garden/INPA/Smithsonian. 264p.

SCOGIN, D. A. et al. 1977. Anthochlor pigments and pollination biology. II The ultraviolet floral patterns of Coreopis gigantea (Asteraceae). Bull. Tor. Botânica. Club, 104 (2): 155-159.

VOGEL, S. 1962. Deftrusen im dienste der bestãaumbung. Akad. Wiss. Abh. Math. Naturhwiss. Kl. 10: 599-763. PLANTAS

Recebido em: 09.04 .97

Aceito em: 08.05 .97

Bol. do Mus. Integrado. de Roraima, Boa Vista, 4 (único): 11-22, 1998 